\title{
ELECTROPHORETIC STUDIES ON SOLUBILIZED PROTEINS OF GOLDFISH BRAIN
}

\author{
RAMON LIM*, GARY A. DAVIS** AND BERNARD W. AGRANOFF \\ Mental Health Research Institute, and Department of Biological Chemistry, University of Michigan. \\ Ann Arbor, Mich. 48104 (U.S.A.)
}

(Accepted July 10th, 1970)

\section{INTRODUCTION}

The disruption of memory formation in goldfish with inhibitors of protein synthesis suggests a possible connection between proteins and memory ${ }^{2}$. Although drugs are convenient tools for an indication of such a relationship, the demonstration of proteins directly involved in the memory process would provide more direct support for this concept. We have previously studied protein metabolism of the goldfish brain based on the incorporation of labeled amino acids into the TCA-precipitable fraction ${ }^{21}$. In this paper we present data on proteins fractionated with polyacrylamide gel electrophoresis, in conjunction with a method for the direct autoradiography of gels and with an enzymatic study of acetylcholinesterase (ChE). Results obtained under various conditions of training are compared. While reports from other laboratories have indicated changes in $\mathrm{RNA}^{13,26,28}$ or protein ${ }^{5,17}$ labeling in various species as a result of training, the present study does not reveal detectable chemical alterations in soluble proteins of the goldfish brain as a result of training.

\section{MATERIALS AND METHODS}

\section{Experimental animals and training conditions}

Common goldfish (Carassius auratus) were obtained and maintained as described previously ${ }^{21}$. Fish were trained to swim over a barrier and to deflect a swinging gate upon a light signal in order to avoid a mild punishing electrical shock ${ }^{1}$. The responses to training in experiments reported were recorded automatically and fell within usual limits. All fish were set out in individual home tanks the day before initial training.

\footnotetext{
* Special Research Fellow, National Institute of Mental Health. Present address: Division of Neurosurgery and Department of Biochemistry, University of Chicago, Chicago, Ill.

** Predoctoral Fellow, National Institute of Mental Health. Present address: Laboratory of Neuropharmacology, National Institute of Mental Health, St. Elizabeths Hospital, Washington, D.C.
} 


\section{Isotopes and chemical reagents}

Labeled amino acids were obtained from Schwarz Bio-Research Inc.. Orangeburg, N.Y. L- $\left[{ }^{3} \mathrm{H}_{4}, 5\right]$ Leucine $(6.0 \mathrm{Ci} / \mathrm{mmole})$, in $0.01 \mathrm{~N} \mathrm{HCl}$ at a concentration of $1 \mathrm{mCi} / \mathrm{ml}$, was injected as such. $\mathrm{L}-\left[\mathrm{U}-{ }^{14} \mathrm{C}\right]$ Leucine $(180 \mathrm{mCi} / \mathrm{mmole})$, in $0.01 \mathrm{~N} \mathrm{HCl}$ at $50 \mu \mathrm{Ci} / \mathrm{ml}$, was neutralized with $\mathrm{NaOH}$ and concentrated by lyophilization to $500 \mu \mathrm{Ci} / \mathrm{ml}$ before use, the final $\mathrm{NaCl}$ concentration being adjusted to $0.15 \mathrm{M}$. Acetyl thiocholine iodide was purchased from Sigma Chemical Co.. St. Louis, Mo. Myrj 53 was a product of Atlas Chemical Industries, Wilmington, Del. Triton X-100 was a gift of Rohm and Haas, Philadelphia, Pa. Dithio-oxamide was purchased from Fisher Scientific Co., Fair Lawn, N.J. 5,5'-Dithiobis(2-nitrobenzoic acid) (DTNB) and diisopropylfluorophosphate (DFP) were obtained from $\mathrm{K}$ and $\mathrm{K}$ Laboratories, Plainview, N.Y.

\section{Chemical procedures}

Methods for the isolation of brain protein and for the determination of radioactivity by liquid scintillation counting were as described earlier ${ }^{21}$. Soluble proteins were fractionated by polyacrylamide gel slab electrophoresis and radioactivity in the bands was studied by autoradiography ${ }^{22}$. The electrophoretic conditions of Davis $^{8}$ were adopted for the slab. Cholinesterase $(\mathrm{ChE})$, which in fish brain is primarily true acetylcholinesterase ${ }^{6}$ (EC 3.1.1.7), in brain homogenate and various extracts was determined spectrophotometrically ${ }^{12}$. For the enzymatic studies, brain tissue was homogenized in $1.0 \%$ Myrj 53 in $0.005 \mathrm{M}$ sodium phosphate buffer, $\mathrm{pH}$ 7. The Myrj extract was obtained by centrifuging a $10 \%$ brain homogenate at $100,000 \times g$ for $1 \mathrm{~h}$. From 7 to $9 \%$ of the $\mathrm{ChE}$ was extracted by this procedure. Addition of Triton X-100 to the Myrj 53 residue solubilized an additional $30-40 \%$ of the enzyme. The electrophoresis resolved the Triton extract into one major and several minor bands of ChE activity. As in rat retina ${ }^{10}$, the Myrj bands showed more diverse metabolic behavior than the Triton bands. For the separation of multiple forms of $\mathrm{ChE}$, disc electrophoresis was carried out as previously described ${ }^{10}$, except that a single separation gel of $6.25 \%$ acrylamide was used. Bands of ChE activity in the gel were detected by a modification of the Koelle histochemical technique ${ }^{19}$. Gels were preincubated at $25-26^{\circ} \mathrm{C}$ in three 10 -min changes of $0.2 M$ sodium phosphate buffer ( $\mathrm{pH} 6.5$ ) containing $0.04 M$ magnesium sulfate, $0.002 M$ copper sulfate and $0.075 \%$ glycine. They were then incubated for $60 \mathrm{~min}$ in this solution with $3 \mathrm{mg} / \mathrm{ml}$ of acetyl thiocholine iodide. Each gel was subsequently washed overnight with shaking in $50 \mathrm{ml}$ of $3 \mathrm{M}$ ammonium sulfate at $4^{\circ} \mathrm{C}^{18}$. The bands of copper thiocholine were converted to copper dithio-oxamide by soaking overnight at $4^{\circ} \mathrm{C}$ in a saturated solution of dithio-oxamide. Gels were transferred to $7 \%$ acetic acid before densitometric scanning. A microdensitometer similar to that of Allen and Jamieson ${ }^{3}$ was used at $500 \mathrm{~nm}$. The peak heights of the bands were proportional within $5 \%$ to incubation time for at least $60 \mathrm{~min}$ and to the amount of enzyme in the range used for these studies. Previous unsuccessful attempts to achieve linearity with dithio-oxamide might have been due to the use of a lower molarity of sulfate ${ }^{10}$.

Brain Research, 25 (1971) 121-131 


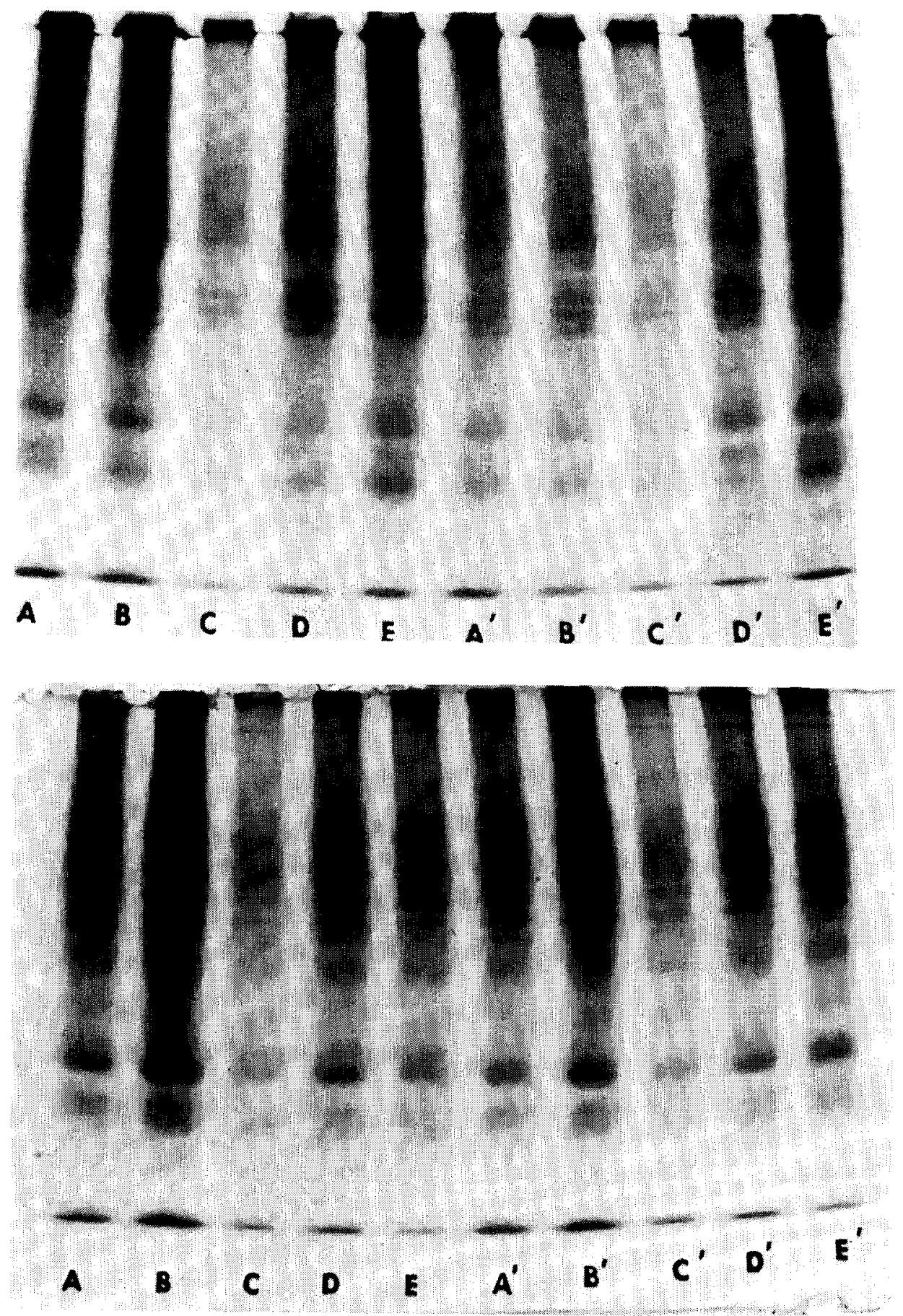

Fig. 1. Autoradiography of proteins following polyacrylamide gel slab electrophoresis. (A) Protein patterns in the gel stained with amido black. (B) Autoradiogram after 6-month exposure. Samples A, $B, C, D$ and $E$ were from the following parts of the trained fish: A, olfactory lobes; B, tectum; C. cerebellum and valvula; $D$, diencephalon plus tegmentum; E, vagal lobes. Samples $A^{\prime}, B^{\prime}, C^{\prime}, D^{\prime}$ and $E^{\prime}$ were from the corresponding parts of the control fish. 
RESULTS

Autoradiographic studies on soluble brain proteins fractionated by acrytamide gel electrophoresis

Sixty goldfish were each subjected to a session of $30 \mathrm{l}-\mathrm{min}$ shock-avoidance trials. Each fish was injected intraperitoneally (i.p.) with $20 \mu \mathrm{Ci}$ of $\left[{ }^{3} \mathrm{H}\right]$ leucine $5 \mathrm{~min}$ before training and killed 5 min after training. Control fish were stored in their home tanks during the 40-min labeling period. Trained fish did not show a significant increase in isotope incorporation into brain protein or in the ratio of the radioactivity in protein to that in the TCA-soluble fraction ${ }^{21}$. It remained possible that detectable alterations were present in specific proteins in the TCA-precipitable fraction. Subsequently the $100,000 \times g$ supernatant fraction, which contains about hatf of the radioactivity present in the TCA-insoluble fraction, was fractionated by electrophoresis and autoradiographed. For these experiments, a group of 5 fish received 301 -min shock-avoidance trials in a period of $30 \mathrm{~min}$ and were then returned to the home tanks. Each fish was injected intracranially (i.c.) with $10 \mu \mathrm{Ci}$ of $\left[{ }^{14} \mathrm{C}\right]$ leucine in $20 \mu \mathrm{l}$ of isotonic saline immediately before training and was killed $2 \mathrm{~h}$ later. Five control fish were injected but were not trained, and remained in the home tanks throughout the experiment. The brains were dissected and similar regions from 5 fish were pooled, homogenized in $0.5 \mathrm{ml}$ of water and centrifuged at $100,000<g$ for $1 \mathrm{~h}$ to obtain the soluble fraction. Of each supernatant fraction $50 \mu \mathrm{l}$ were mixed with the sample gel solution in each slot in the acrylamide gel slab prior to polymerization. The proteins were fractionated by electrophoresis and were stained and autoradiographed. Duplicate gels using the same samples as well as duplicate groups of fish treated similarly gave essentially the same results as those shown. As can be seen in Fig. 1, differences in stained protein patterns or in isotope incorporation were not clearly detectable among the various brain regions. Training did not appear to result in any unequivocal alterations in either the degree of staining or the radioactivity of bands. On the other hand, there were striking differences in pattern between autoradiograms and stained gels (Fig. 2), suggesting different rates of turnover for the individual proteins, although we did not examine other times of incorporation. About 30 bands are seen in both the gel and in the autoradiogram, while 11 additional bands are seen only by either staining or autoradiography.

\section{Turnover studies on ChE}

Fig. 3 shows the enzyme patterns obtained by acrylamide electrophoresis of the Myrj 53 extract of different regions of the goldfish brain. Variations between regions are seen, particularly in bands 2 and 3. The turnover of ChE was determined by means of DFP inhibition (Fig. 4). Goldfish were injected i.c. ${ }^{7}$ with $10 \mu \mathrm{l}$ of $0.1 \mathrm{M}$ DFP in dry propylene glycol. Controls received the vehicle alone. Two hours after DFP, ChE activities in total brain and subfractions were all reduced to $5-10 \%$ of controls. The gross behavior of the treated animals could not be distinguished from 


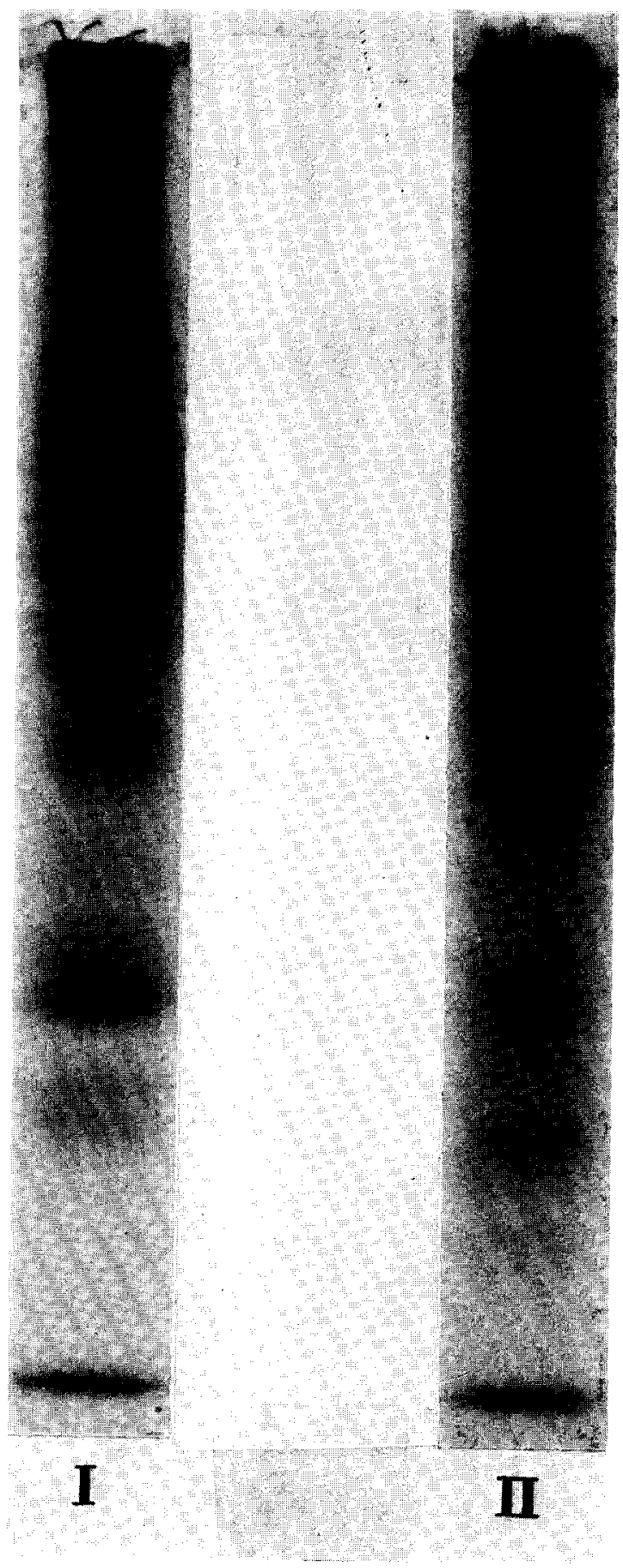

Fig. 2. Detail of staining pattern and radioactivity of protein bands. Parts D of the trained fish from Fig. 1 were cut out and matched. I, staining pattern; II, autoradiogram. 


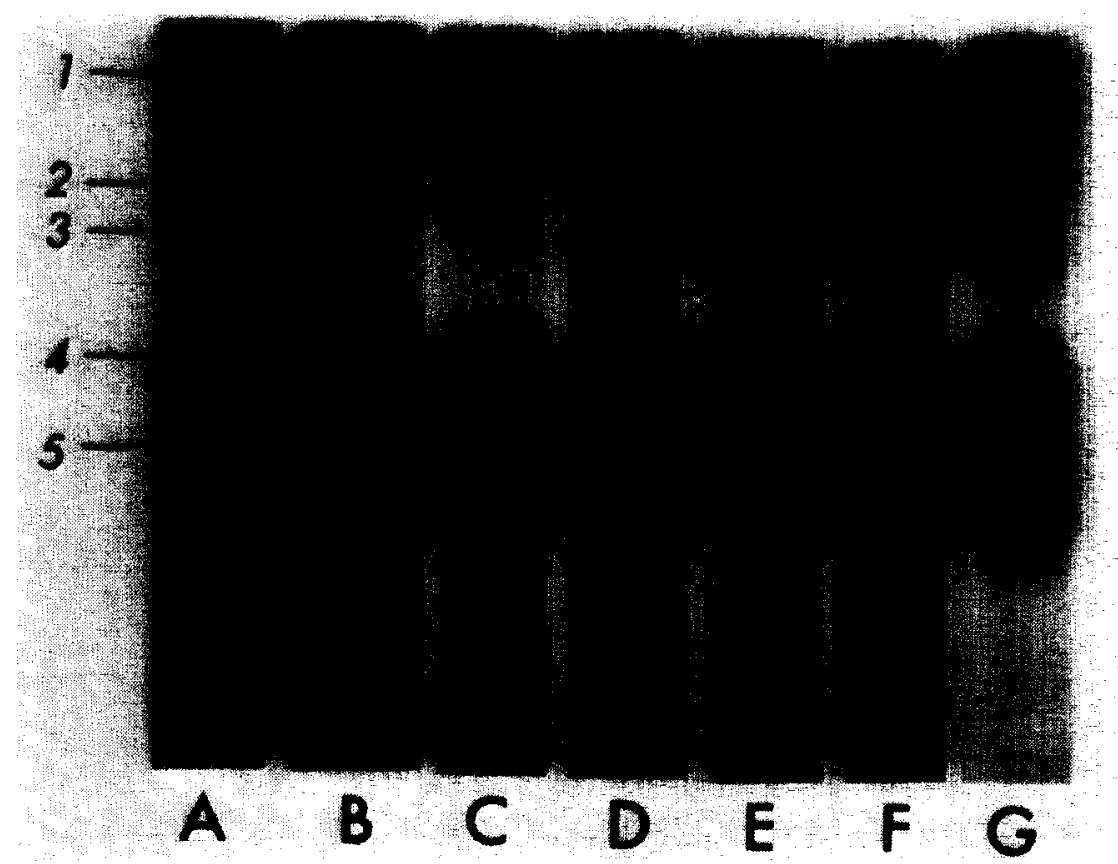

Fig. 3. Electrophoretic patterns of $\mathrm{ChE}$ in selected areas of goldfish brain. A, whole brain; B, olfactory lobes; $C$, diencephalon; $D$, tegmentum; $E$, cerebellum plus valvula; $F$, medulla posterior part minus the vagal lobes; $G$, vagal lobes.

controls, although 3 animals out of 100 died. The brains from 5-6 fish were pooled before extraction, and 2-3 pools were used for each time point. Two control groups were killed at 1 day, one at 10 days and one 28 days after injection. Recoveries of corresponding bands of the Myrj extracts from the pooled control groups were all within $5 \%$ of one another with the exception of bands 2 and 3 at 28 days. The homogenate, Myrj 53 extract, sample gel and band 1 exhibited generally similar patterns of recovery (Fig. 4) with an early rapid phase followed by a slower phase. In the homogenate there was some indication of a third, even slower phase. The half-lives of the early phases were about 2.6 days in the homogenate, 2.3 days in the Myrj 53 extract and 3.5 days in band 1. For the later phases the half-lives were roughly 32 days, 40 days and 21 days, respectively. The absorption values for the sample gel were too irregular to permit reliable calculation. Bands 2 to 5 of the Myrj extract showed modes of recovery distinct from that of the bulk of the ChE. Bands 4 and 5 behaved in a quite similar fashion to one another, exhibiting a phase of very rapid recovery with a half-life of about one day. After reaching about $70 \%$ of control, values of the bands underwent no further steady increase. Bands 2 and 3 also behaved alike with a halflife for recovery of about 1.7 days. At the later time points these bands overshot control levels by considerable amounts, as indicated. A Triton X-100 extract of the Myrj residue was prepared 7 days after DFP. All the Triton bands exhibited a recovery of $43 \%$, a rate close to the recovery $(45 \%)$ in the homogenate at that time. 

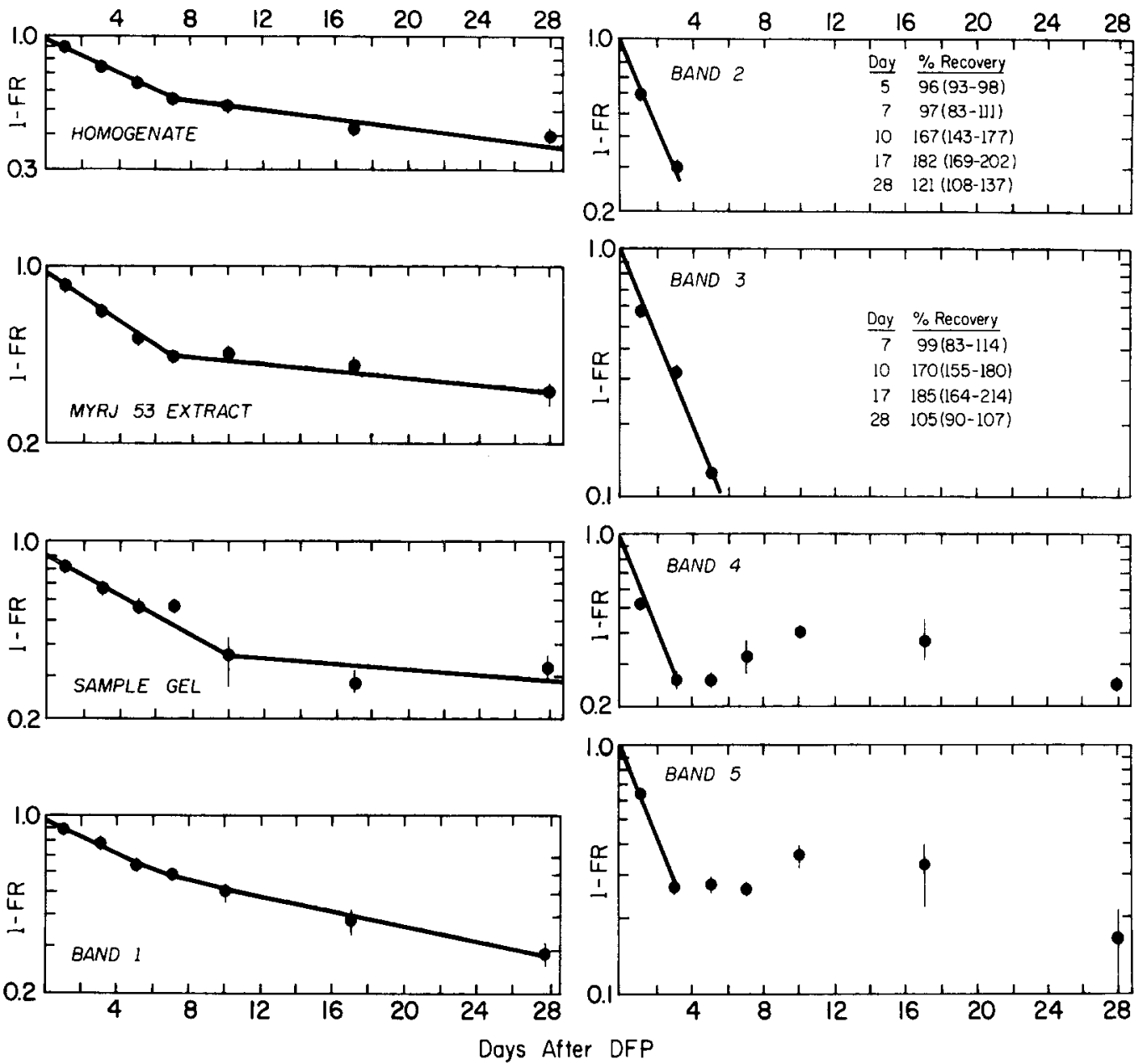

Fig. 4. Recovery of various fractions of ChE in extracts of whole goldfish brain after inhibition by DFP. The values for the sample gel and bands are from optical scans of disc electrophoretic separations of the Myrj 53 extract. FR = fractional recovery. Circles are means, and bars delineate the range. The ordinates are expressed as 1 -FR $(=$ fractional recovery $)$, plotted logarithmically ${ }^{24}$.

\section{Effect of training on ChE levels}

To evaluate the possible effects of training, 3 groups of 20 fish were set out in individual home tanks for one day. Group A was then trained on days 1, 4 and 7. Group B was trained on day 7. Group C was not trained. Each training session consisted of 20 shock-avoidance trials in $20 \mathrm{~min}$, and the fish were kept in the home tanks in between sessions. Groups A and B were killed 10 min after returning to home tanks following training. Group $C$ was killed on day 7 without being exposed to the training environment. Whole brains from each group were pooled in groups of 5 for extraction with Myrj 53 and analysis of ChE activity. ChE activities in fish that underwent training were slightly higher than the control values in most fractions examined (Table I), but analyses did not establish significant differences. 
TABLE I

ChE ACTIVITIES IN FISH BRAIN AFTER TRAINING

Values are averages of 4 duplicate groups of 5 fish.

\begin{tabular}{|c|c|c|c|}
\hline & \multicolumn{3}{|c|}{ nmoles substrate hydrolyzed/min/mg wet weight ( $t S . D)}$. \\
\hline & $\begin{array}{l}\text { Multiple training } \\
\text { sessions }\end{array}$ & $\begin{array}{l}\text { Single training } \\
\text { session }\end{array}$ & Untrained \\
\hline Homogenate & $15.70=0.30$ & $15.20 \div 0.70$ & $14.70-0.90$ \\
\hline \multirow[t]{2}{*}{ Myrj 53 extract } & $0.96 \div 0.06$ & $1.02 \div 0.17$ & $0.90 \div 0.15$ \\
\hline & \multicolumn{3}{|c|}{ Optical density S.D. } \\
\hline Sample gel & $0.43 \pm 0.02$ & $0.50 \div 0.03$ & $0.41-0.05$ \\
\hline Band 1 & $0.71: 0.05$ & $0.71-0.12$ & $0.69 \therefore 0.04$ \\
\hline Band 2 & $0.25+0.01$ & $0.28 \pm 0.04$ & $0.24: 0.02$ \\
\hline Band 3 & $0.16+0.01$ & $0.18 \pm 0.03$ & $0.17 \div 0.02$ \\
\hline Band 4 & 0.720 .04 & $0.74+0.11$ & $0.67+0.04$ \\
\hline Band 5 & $0.87 \quad 0.07$ & $0.96+0.13$ & $0.88+0.08$ \\
\hline
\end{tabular}

DISCUSSION

This laboratory is engaged in studies employing antibiotic inhibitors of macromolecular synthesis to gain further insight on the molecular basis of memory storage ${ }^{2}$. Although such inhibition studies suggest a role for protein in the formation of longterm memory in the goldfish, they do not by their nature yield highly selective information concerning which proteins or which metabolic process is most closely related to the amnestic effect produced by the blocking agents during the period that follows training ${ }^{2}$. We attempted to determine whether there was a difference in labeling of brain proteins under the conditions of training compared to those of rest in the home tank environment during a 40-min period following i.p. injection of $\left[{ }^{3} \mathrm{H}\right]-$ leucine. While such experiments in our hands have not revealed significant changes in the TCA-precipitable fraction of whole goldfish brain, it remained possible that an alteration in a subpopulation of protein, perhaps in a specific brain area, was obscured by the relatively gross technique employed. In the present study, the 100,000 $\times g$ fraction of homogenates of 5 brain regions (Fig. 1) were investigated following in vivo labeling. In this instance $\left[{ }^{14} \mathrm{C}\right]$ leucine was used instead of $\left[{ }^{3} \mathrm{H}\right]$ leucine because of the higher energy beta-emission required for direct autoradiography of the gels. The period of labeling was extended to include a 1.5 -h period following training, so that changes in protein synthesis elicited by consolidation of memory as well as by training would seem more likely to be detected. Even with this relatively refined technique, careful comparison between the trained and the control fish failed to reveal definite protein alterations, either in the staining pattern or in the autoradiogram (Fig. 2). Our inability to observe changes in protein and radioactive patterns should by no means be taken to negate the possibility of participation of protein molecules in the memory process, for such changes might well escape detection by our analytical methods. Alterations might take place in the insoluble protein fraction, 
which was not separated by our procedure. Our work does, however, question the universality and biological significance of results in other animals in which sizeable chemical alterations are detected. For example, gross changes in staining patterns in a DEAE cellulose elution pattern of pigeon brain was reported by Bogoch following training ${ }^{5}$. Glassman et al. ${ }^{14}$ and Shashoua ${ }^{26}$ reported increases in RNA labeling and a change in RNA base ratios, respectively, in goldfish brain as a result of training. Such detectable alterations in RNA might be expected to result in detectable changes in protein.

The lack of difference in staining and in protein labeling from area to area of brain and to behavioral stress suggested that some more responsive measure of brain proteins be examined. Since electrophoretically distinct forms of enzyme are known to vary from organ to organ within a single animal15, we examined the possibility that such differences would be reflected in the brain areas studied. ChE was selected because of the general importance of acetyl choline as a neurotransmitter and because a number of studies, 41,25 have suggested its involvement in higher brain function.

The brain areas examined exhibited marked differences in ChE bands, unlike our observations with dye staining and labeled protein distribution. No alteration in the electrophoretic bands of $\mathrm{ChE}$ in a goldfish brain homogenate was detected following the training procedure (Table I). In other experiments with Myrj 53soluble fractions from rats subjected to impoverished or enriched environments for long periods of time, changes in the enzyme electrophoretic patterns were also absent ${ }^{9}$. Nevertheless, it is suggested by the present study that analyses of specific enzymes are more likely to lead to proteins putatively related to behavioral change than less selective procedures.

ChE bands of the goldfish brain exhibited varying half-lives for the individual bands, suggesting that enzyme patterns in the gel are not artifactually produced from one $\mathrm{ChE}$ molecule. The return of ChE activity studied in homogenates after in vivo DFP inhibition is generally similar for goldfish brain, rat retina ${ }^{10}$ and rat brain areas ${ }^{15}$ in that a two-phase log recovery curve is observed. The half-lives in rat are generally shorter than in goldfish. One $\mathrm{ChE}$ band in rat was found to have a very short halflife of $3 h^{10}$. Over-recovery of enzyme activity after DFP inhibition was observed in some ChE bands of fish brain. Similar phenomena have been noted in other animals by a number of authors $9,15,20,23$ and it has been suggested that they may be mediated by enzyme induction.

The significance of proteins having similar catalytic activities but different electrophoretic mobilities is still a matter for conjecture. They may reflect action of different genes, various combinations of subunit polypeptides or partial conjugation or degradation of parent proteins ${ }^{16}$. As stated above, the pattern of reappearance of enzymic activity of ChE following DFP did not support this latter possibility. The regions sampled in the present study were selected as a matter of convenience. Division into smaller brain areas might show even greater differences among regions. Because of its complex architecture, it is not surprising that different brain regions exhibit differences commonly seen between organs. The functional significance of the multiple forms remains obscure and it is likely that their regional and temporal 
variability may be due to many factors. It is tempting to speculate that among these the multiple forms of $\mathrm{ChE}$ in goldfish brain may be related to temperature regulation as has been proposed for other multiple enzyme forms in poikilothermis ${ }^{2 i}$.

SUMMARY

Soluble proteins from homogenates of various regions of goldfish brain have been separated by gel electrophoresis techniques. Distribution of radioactive proteins formed following injection of a labeled amino acid was studied by direct autoradiography of gel slabs. While dye staining and labeling patterns of electrophoretically separated proteins did not vary among brain regions examined, there were marked differences in the position of stained bands and those detected autradiographically, suggesting diverse rates of metabolism of these soluble proteins. Unlike the protein staining and labeling patterns, the distribution of multiple electrophoretic bands of solubilized acetylcholinesterase varied among the 5 brain regions examined. Protein bands detected either by dye staining, autoradiography or by acetylcholinesterase activity did not vary measurably as a result of shock-avoidance training of the goldfish. In further studies with DFP, apparent turnover rates for the multiple forms of acetylcholinesterase in a detergent extract of whole brain were determined.

\section{ACKNOWLEDGEMENTS}

We thank Mr. J. J. Huang and Mrs. E. Tadayyon for very able technical assistance on chemical work, and Mr. P. D. Klinger for training the goldfish.

This investigation was supported by grants from the National Science Foundation and the National Institute of Mental Health (MH-12506).

\section{REFERENCES}

1 Agranoff, B. W., and Davis, R. E., The use of fishes in studies on memory formation. In D. INGLE (Ed.), The Central Nervous System and Fish Behavior, Univ. of Chicago Press, Chicago, IIl., 1968, pp. 193-201.

2 Agranoff, B. W., Davis, R. E., And Brink, J. J., Chemical studies on memory fixation in goldfish, Brain Research, 1 (1966) 303-309.

3 Allen, R. C., AND Jamieson, G. R. An automated densitometer for the quantitation of pherograms and zymograms in acrylamide gels, Anal. Biochem., 16 (1966) 450-456.

4 Bennett, E. L., Diamond, M. V., KReCH, D., ANd Rosenzweig, M. R., Chemical and anatomical plasticity of brain, Science, 146 (1964) 610-619.

5 Bogoch, S., The Biochemistry of Memory, Oxford Univ. Press, New York, 1968.

6 BRIK. I. L., Characteristics of acetylcholine esterase from the brain of carp, Biokhimiya, 34 (1969) 90-95.

7 BRINK, J. J., Davis, R. E., AND Agranoff, B. W., Effects of puromycin, acetoxycycloheximide and actinomycin D on protein synthesis in goldfish brain, J. Neurochem., 13 (1966) 889-896.

8 Davis, B. J., Disc electrophoresis. II, Ann. N.Y. Acad. Sci, 121 (1964) 404-427.

9 Davis, G. A., The Behavior of Multiple Molecular Forms of Cholinesterase, Ph. D. Thesis, Univ. of Michigan, Ann Ärbor, 1968.

10 Davis, G. A., AND Agranoff, B. W., Metabolic behaviour of isozymes of acetylcholinesterase, Nature (Lond.), 220 (1968) 277-280.

Brain Research, 25 (1971) 121-131 
11 Deutsch, J. A., Hamburg, M. D., And Dahl, H., Anticholinesterase-induced amnesia and its temporal aspects, Science, 151 (1966) 221-223.

12 Ellman, G. L., Courtney, K. D., Andres, V., Jr., and Featherstone, R. M., A new and rapid colorimetric determination of acetylcholinesterase activity, Biochem. Pharmacol., 7 (1961) 88-95.

13 Gaito, J., Unique RNA species in behavioral tasks, Amer. J. Orthop., 38 (1968) 232-233.

14 Glassman, E., Schlesinger, K., AND Wilson, J., Increased synthesis of RNA in the brains of goldfish during short term learning experiences, Fed. Proc., 25 (1966) 713.

15 Glow, P. H., Rose, S., And Richardson, A., The effect of acute and chronic treatment with diisopropylfluorophosphate on cholinesterase activities of some tissues of the rat, Aust. J. exp. Biol. med. Sci, 44 (1966) 73-86.

16 Harris, H., Genes and isozymes, Proc. roy. Soc. B, 174 (1969) 1-31.

17 Hydén, H., ANd LANGe, P. W., Protein synthesis in the hippocampal pyramidal cells of rats during a behavioral test, Science, 159 (1968) 1370-1373.

18 JuUl, P., Human plasma cholinesterase isozymes, Clin. chim. Acta, 19 (1968) 205-213.

19 KoElle, G. B., The elimination of enzymatic diffusion artifacts in the histochemical localization of cholinesterases and a survey of their cellular distribution, J. Pharmacol. exp. Ther., 103 (1951) $153-171$.

20 Koelle, G. B., and Gilman, A., The relationship between cholinesterase inhibition and the pharmacological action of di-isopropyl fluorophosphate (DFP), J. Pharmacol. exp. Ther, 87 (1946) $421-434$.

21 Lim, R., ANd Agranoff, B. W., Protein metabolism in goldfish brain, J. Neurochem., 16 (1969) $431-445$.

22 Lim, R., Huang, J. J., AND Davis, G. A., Autoradiography with acrylamide gel slab electrophoresis, Anal. Biochem., 29 (1969) 48-57.

23 Locker, A., Und Siedek, H., Über Aktivierung von Cholinesterasen durch Alkylphosphate in vivo, Experientia (Basel), 8 (1952) 146-148.

24 Rechcigl, M., JR., AND Heston, W. E., Genetic regulation of enzyme activity in mammalian system by the alteration of the rates of enzyme degradation, Biochem. biophys. Res. Commun., 27 (1967) 119-124.

25 SAUNDERS, V. F., Effect of behavioral and environmental manipulations on central cholinesterase activity in the rat, Fed. Proc., 25 (1966) 385.

26 Shashoua. V. E., RNA changes in goldfish brain during learning, Nature (Lond.), 217 (1968) $238-240$.

27 Somero, G. N., AND Hochachкa, P. W., Isoenzymes and short-term temperature compensation in poikolotherms: Activation of lactate dehydrogenase isoenzymes by temperature decreases, Nature (Lond.), 223 (1969) 194-195.

28 Zemp, J. W., Wilson, J. E., Schlesinger, K., Boggan, W. O., and Glassman, E., Brain function and macromolecules. I. Incorporation of uridine into RNA of mouse brain during short-term training experience, Proc, nat. Acad. Sci. (Wash.), 55 (1966) 1423-1431. 